University of Nebraska - Lincoln

DigitalCommons@University of Nebraska - Lincoln

Synthetic host volatiles increase efficacy of trap cropping for management of Colorado potato beetle, Leptinotarsa decemlineata (Say)

\author{
J. W. Martel \\ University of Maine
}

A. R. Alford

University of Maine, alford@maine.edu

J. C. Dickens

USDA-ARS

Follow this and additional works at: https://digitalcommons.unl.edu/usdaarsfacpub

Martel, J. W.; Alford, A. R.; and Dickens, J. C., "Synthetic host volatiles increase efficacy of trap cropping for management of Colorado potato beetle, Leptinotarsa decemlineata (Say)" (2005). Publications from USDA-ARS / UNL Faculty. 1437.

https://digitalcommons.unl.edu/usdaarsfacpub/1437

This Article is brought to you for free and open access by the U.S. Department of Agriculture: Agricultural Research Service, Lincoln, Nebraska at DigitalCommons@University of Nebraska - Lincoln. It has been accepted for inclusion in Publications from USDA-ARS / UNL Faculty by an authorized administrator of DigitalCommons@University of Nebraska - Lincoln. 


\title{
Synthetic host volatiles increase efficacy of trap cropping for management of Colorado potato beetle, Leptinotarsa decemlineata (Say)
}

\author{
J. W. Martel, A. R. Alford and J. C. Dickens* \\ Department of Biological Sciences, University of Maine, Orono, ME 04469, U.S.A. and*USDA-ARS, Henry A. Wallace Beltsville Agricultural \\ Research Center, Plant Sciences Institute, Chemicals Affecting Insect Behaviour Laboratory, Beltsville, MD 20705, U.S.A.
}

\begin{abstract}
The attractiveness of pitfall traps baited with a synthetic host volatile attractant to colonizing adult Colorado potato beetle, Leptinotarsa decemlineata (Say) was evaluated in a field setting.

2 Significantly more postdiapause, colonizing adult $L$. decemlineata were captured in baited than unbaited pitfall traps.

3 The potential for this synthetic kairomone to enhance the efficacy of trap cropping as a management tool was evaluated by comparing conventionally managed plots with like-sized plots bordered by either attractant-treated trap crop or untreated trap crop.

4 More postdiapause, colonizing adults, egg masses and small larvae were present in attractant-treated trap crops than in untreated trap crops.

5 There were no significant differences in egg mass and small larvae densities between plots bordered by attractant-treated trap crops and conventionally managed plots, but there were significantly fewer large larvae and adult beetles in conventionally managed plots.

6 Plant canopy area of conventionally managed plots was significantly greater than in plots bordered by either type of trap crop.

7 Yields for conventionally managed plots and plots bordered by attractanttreated trap crops did not differ, and less insecticide (44\%) was applied to plots bordered by attractant-treated trap crops.
\end{abstract}

Keywords Attractant, kairomone, Colorado potato beetle, plant volatiles, semiochemicals.

\section{Introduction}

The Colorado potato beetle, Leptinotarsa decemlineata (Say), is considered one of the most destructive insect pests of cultivated potato, Solanum tuberosum L., in North America and Europe. It is of particular concern because it has developed resistance to a wide variety of conventional insecticides (Forgash, 1985; Boiteau, 1988; Hare, 1990; Ioannidis et al., 1991; French et al., 1992; Olkowski et al., 1992; Kennedy \& French, 1994; Stewart et al., 1997), as well as Bacillus thuringiensis subspecies tenebrionis CryIIIA

Correspondence: A. R. Alford. Tel: +1 207581 2964; fax: +1 207581 2969; e-mail: alford@maine.edu delta-endotoxin in the laboratory (Whalon et al., 1993; Rahardja \& Whalon, 1995). Increased public concern regarding the long-term effects of conventional insecticide use on human and environmental health has made it necessary to develop alternative management strategies that reduce the environmental impact of agricultural pest management and decrease this pest's capacity for development of resistance to chemical controls (Casagrande, 1987; Hare, 1990; Shani, 1991; Smart et al., 1994; Ioriatti \& Bouvier, 2000).

Trap crops are plantings grown for the purpose of drawing insect pest populations away from economic regions of production systems where they may be effectively managed and reduced before causing economic damage. By manipulating spatial and temporal aspects of a crop ecosystem, 
invading pest populations can be aggregated in trap crop regions and densities reduced with well-timed, highly selective insecticide application (Hokkanen, 1991). If effective larval control is achieved in the first generation, damage from subsequent $L$. decemlineata generations could be minimal (Wyman, 1995).

Early planted potato trap cropping, used to aggregate L. decemlineata for chemical management, has been practiced in the former Soviet republic of Belarus from 1957 onward (Dorozhkin et al., 1975). Trap crops planted 5-10 days before main crops (sized 5\% of main crop area) were recommended for $L$. decemlineata management in Bulgaria (Bozhkov, 1985). Chausov (1976) reported that $2-5$ ha of trap crop provided sufficient protection for 200-500 ha of main economic crop in Russia, such that the number of insecticide applications in the main crop was reduced from two to one per growing season.

The attractiveness of trap crop plantings to insect pests might be further enhanced by application of attractive semiochemicals, such as insect pheromones or plant kairomones (Hardee, 1982; Metcalf, 1985). Because L. decemlineata is attracted to volatiles emanating from host plants in laboratory bioassays (McIndoo, 1926; Schanz, 1953; DeWilde, 1976; Visser \& Avé, 1978; Bolter et al., 1997; Landolt et al., 1999), it is possible that synthetic blends of host volatiles (Dickens, 1999, 2000, 2002) could be used to augment the attractiveness of trap crops to colonizing adults in the field. Subsequent insecticide application to a trap crop after colonization may decrease the frequency of application, spray area, total volume and associated management costs for a crop system at the same time as maintaining adequate pest control.

Whole-field insecticide applications can create strong selection pressure for resistance development (Olson et al., 2000; Zhao et al., 2000). Because insecticide application in main economic crop areas was reduced by $50 \%$ in Chausov's (1976) system when grown in the presence of an early planted trap crop, L. decemlineata were exposed to one less major selection event than those in areas not protected by a trap crop. A reduction in the number of insecticide applications may better maintain a balance of susceptible and resistant genotypes within a pest population. It may also serve the dual purpose of decreasing the likelihood of resistance development at the same time as reducing the impact of conventional pest management on nontarget organisms and the production environment, such as in 1979 when the carbamate aldicarb was implicated in the contamination of residential wells on Long Island, New York, after use against L. decemlineata (Jones \& Marquardt, 1987).

In the present study, the first objective was to assess the attractiveness of a synthetic host volatile blend discovered by Dickens $(1999,2000,2002)$ to postdiapause, colonizing $L$. decemlineata in a field setting. The second objective was to determine whether the synthetic host volatile blend could augment the efficacy of early planted trap crops deployed for $L$. decemlineata management.

\section{Materials and methods}

\section{Pitfall trap study}

This study was initiated before plant emergence and conducted from 5 June to 20 June 2000 in two potato fields ( 0.30 and 0.10 ha, respectively) at the University of Maine Agricultural and Forest Experiment Station Rogers Farm, Stillwater, Maine.

Twenty-two pitfall traps were evenly spaced at $10-\mathrm{m}$ intervals around the perimeter of the 0.30 ha field, and 20 traps were evenly spaced at $10-\mathrm{m}$ intervals around the perimeter of the 0.10 ha field to test whether the synthetic volatile attractant blend attracted postdiapause, colonizing adult $L$. decemlineata. In both fields, odd numbered traps were baited and even numbered traps served as controls. Insects were collected from pitfall traps daily between 12.00 and $14.00 \mathrm{~h}$ (EST) for the duration of the experiment.

Traps consisted of 20.3-cm diameter plastic flower pots dug into the soil. Pot rims lay flush with ground level. One $0.61-\mathrm{m}$ iron rod was driven $15.2 \mathrm{~cm}$ through the bottom of each pot to secure it in place, and green plastic foliage painted with John Deere Yellow ${ }^{\mathrm{TM}}$ spray paint (SherwinWilliams Company, Cleveland, Ohio) was attached to the upper portion of the rod to provide an attractive plant model. Zehnder \& Speese (1987), Van der Ent \& Visser (1991) and Boiteau (2000) reported that yellow is attractive to L. decemlineata. Four 1.27-cm holes located on the pot floor allowed rainwater to drain freely.

The three-component plant attractant (Dickens, 2000, 2002) comprised ( $Z$ )-3-hexenyl acetate $98 \%$ (Sigma Chemical Co., St Louis, Missouri) (+/-)-linalool $97 \%$ (Sigma Chemical Co.) and methyl salicylate 99\% (Aldrich Chemical Co., St Louis, Missouri). Cigarette filters (7.1 mm diameter $\times 2.54 \mathrm{~cm}$ length) made of cellulose acetate and wrapped in Saran ${ }^{\mathrm{TM}}$ (Filtrona Richmond Inc., Richmond, Virginia) served as release substrates for the attractant. Three microlitres of each attractant component were diluted in $0.5 \mathrm{~mL}$ of a slow release formulation comprising polyethylene glycol (20\%), methanol (42.5\%), glycerol $(25 \%)$ and distilled water $(12.5 \%)$ (Dickens, 1989) and then injected into the cigarette filters. Control filters contained only $0.5 \mathrm{~mL}$ of the slow release formulation.

A cigarette filter containing either the volatile-baited or control solution was secured by wire in the open side of a 5.1-cm diameter Petri dish. This one-sided plastic lure assembly enabled release of volatiles at the same time as providing weather protection for the cigarette filters. Two lure assemblies were attached to every trap. One was suspended from a hook on the iron rod adjacent to the plastic foliage and hung above the pot rim. The second lure assembly was suspended from a hook on the iron rod and hung inside the pot, $5.1 \mathrm{~cm}$ below ground level. Lures were replaced weekly. The interior rim surface of all traps was covered with the clear, nondrying adhesive Tanglefoot ${ }^{\mathbb{B}}$ (Tanglefoot, Grand Rapids, Michigan) to inhibit escape of beetles. SAS PROC TTEST (paired $t$-test) (SAS Institute, Inc., Cary, North Carolina) was used to analyse total mean 
L. decemlineata density in attractant-baited vs. control pitfall traps.

\section{Determination of volatile release rate}

The rates of release for attractant components were determined using an automated volatile collection system (Analytical Research Systems, Inc., Gainesville, Florida) modified from one described by Heath \& Manukian (1994). These methods are described in detail elsewhere (Dickens, 2002). In brief, a single cigarette filter containing the attractant as above was placed in a 5-L volatile collection chamber from which volatiles were collected for eight, 6-h periods by programming the switching of eight ports of a manifold holding volatile collection traps containing SuperQ adsorbent. This procedure was completed twice for two attractant containing filters $(16 \times 6$-h collections). Volatiles were extracted from each trap with $100 \mu \mathrm{L}$ of hexane, of which $50 \mu \mathrm{L}$ were collected in $300 \mu \mathrm{L}$ cone vials. $\mathrm{N}$-decane $(10 \mathrm{ng})$ was added to each sample as an internal standard. One microlitre samples were injected into a Hewlett Packard ${ }^{\mathrm{TM}}$ Model 5890 A (Hewlett Packard, Palo Alto, California) gas chromatograph (GC) equipped with an HP-5 capillary column (Crosslinked 5\% PH ME Siloxane; film thickness $0.25 \mu \mathrm{m}$; length $30 \mathrm{~m}$; inner diameter $0.25 \mathrm{~mm}$ ) and flame ionization detector (FID). The GC was programmed to hold an initial temperature of $50^{\circ} \mathrm{C}$ for $2 \mathrm{~min}$ after injection, increase $15^{\circ} \mathrm{C}$ per min to $235^{\circ} \mathrm{C}$, and hold for $8 \mathrm{~min}$. The mean release rate for each component of the attractant was determined for the 16, 6-h periods. Hourly release rates were approximated based on these data.

\section{Trap crop study}

Trap crop plots measuring $13.7 \mathrm{~m} \times 4.1 \mathrm{~m}$ (four rows; $55.7 \mathrm{~m}^{2}$ ) were planted with certified $S$. tuberosum (var. Russet Burbank) seed on 24 May 2002 at the University of Maine Agricultural and Forest Experiment Station Rogers Farm (Stillwater, Maine) (Fig. 1). Test plots measuring $13.7 \times 34.6 \mathrm{~m}\left(474.2 \mathrm{~m}^{2}\right)$ were planted with the same variety on 10 June 2002, and were either conventionally managed or bordered on two sides by trap crops (Fig. 1). Trap crops were either untreated or treated with a synthetic host volatile attractant discussed below (Fig. 1). Postplanting roto-tilling provided $2.0 \mathrm{~m}$ bare ground separation between plots bordered by trap crops and conventional plots along with $4.0 \mathrm{~m}$ bare ground separation between field halves. A single $13.7 \times 34.6 \mathrm{~m}$ untreated reference control plot was established on the same farm in a field $0.40 \mathrm{~km}$ away from the trap crop study (same variety and planting date as test plots above) for the purpose of demonstrating unmanaged insect population development without serving as a pest reservoir that could infest the experimental plots. Insect data from this location are included for reference purposes only and were not included in any statistical analysis.

A slow release formulation of the synthetic host volatile attractant provided by Trécé Incorporated (Salinas,
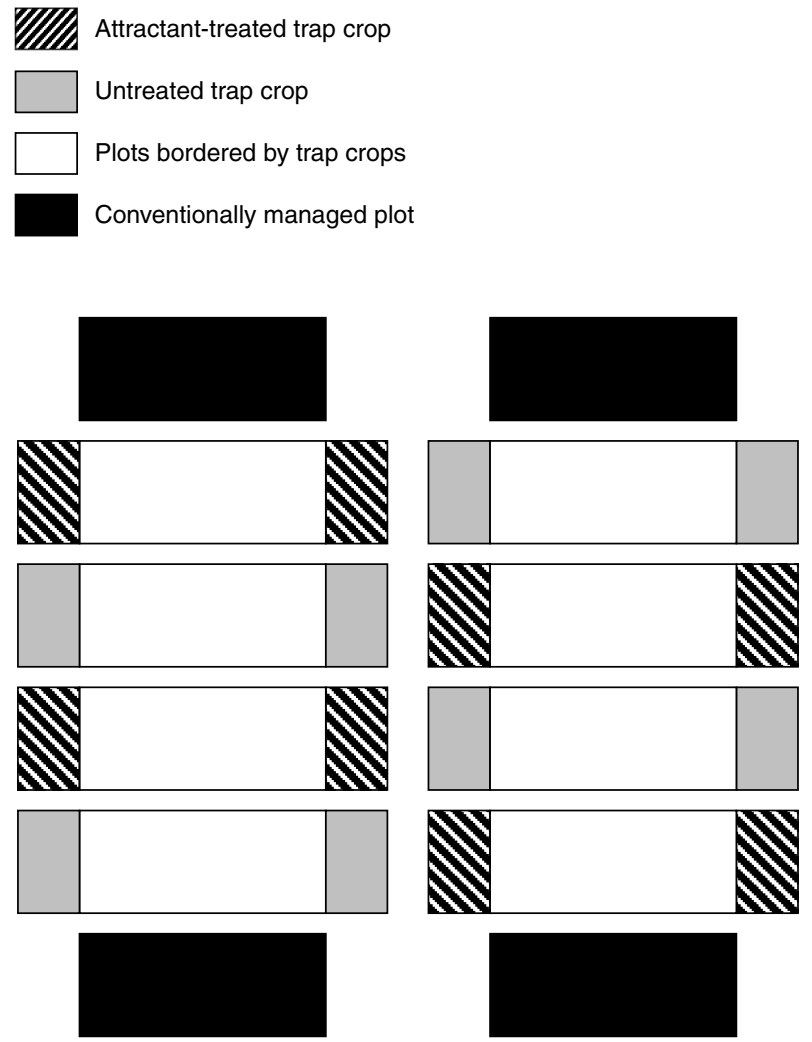

Figure 1 Experimental design of potato field divided into conventionally managed plots and plots bordered by attractant-treated or untreated trap crops.

California) was applied weekly to attractant-treated trap crops at a rate of $1.1 \mathrm{~mL} /$ row-metre using a tractor-mounted, $\mathrm{CO}_{2}$-driven device. The Trécé formulation was a proprietary matrix comprising $5 \%$ by weight of the three attractant components: (Z)-3-hexenyl acetate $(+/-)$-linalool and methyl salicylate. Release rates of attractant components under laboratory conditions previously derived for $1 \mathrm{~mL}$ of the matrix were: $(Z)$-3-hexenyl acetate, $65.4 \mu \mathrm{g} / \mathrm{h} ;(+/-)$ linalool, $75.0 \mu \mathrm{g} / \mathrm{h}$; and methyl salicylate, $42.3 \mu \mathrm{g} / \mathrm{h}$, or approximately $182.7 \mu \mathrm{g}$ total volatile release $/ \mathrm{h}$ (Martel et al., 2004). These release rates are only approximations and are for comparison purposes only. Actual release rates in a potato field are likely to vary based on the size of individual droplets, and prevailing temperature, humidity and wind conditions, as well as other factors.

Trap crop sampling of $L$. decemlineata life stages began at plant emergence (7 June 2002). Twenty-four plants were sampled at random twice-weekly in each trap crop plot until University of Maine Cooperative Extension economic threshold densities were reached (200 small larvae, 75 large larvae, or 25 adults per 50 plants sampled). At this point, all trap crop areas were sprayed (1 July 2002) with Provado ${ }^{\circledR}$ 1.6 Flowable insecticide $(0.19 \mathrm{~kg} / \mathrm{L}$ active ingredient; Bayer Corporation, Kansas City, Missouri) at commercial application rate $(0.05 \mathrm{~kg} / \mathrm{ha})$. After insecticide application, insect surveys in trap crops ceased. 
After plant emergence (24 June 2002), 50 plants were sampled twice-weekly for $L$. decemlineata egg masses, small larvae (first and second instars), large larvae (third and fourth instars) and adults in plots bordered by trap crops and conventionally managed plots by making two transects from opposing plot corners (' $\mathrm{X}$ ' pattern). Provado ${ }^{\circledR} 1.6$ Flowable insecticide was applied at the rate indicated above to both conventional plots (no trap crop) and plots bordered by trap crops when economic thresholds were exceeded. Due to large annual experimental adult beetle introductions in the past, the farm in which this work was carried out has had unusually high L. decemlineata densities compared with typical commercial conditions in this region of Maine. Within the farm, the experiment was conducted on land previously planted to soybeans as part of a rotation scheme; the nearest potato field from the previous year was $0.2 \mathrm{~km}$ away. The primary sources of postdiapause colonizing beetles were presumed to be small woodlots located $0.05 \mathrm{~km}$ away on the north and south sides of the study site.

Leaf area index (LAI) was measured in conventionally managed plots and plots bordered by trap crops using a LAI-2000 Plant Canopy Analyser (LI-COR, Inc., Lincoln, Nebraska) on 25 July 2002. Each plot was sampled at dawn (per manufacturer direction) by conducting two opposing corner transects with four randomly selected sample points each. Three LAI measurements were taken at each sample point (canopy area $\mathrm{m}^{2} /$ ground area $\mathrm{m}^{2}$ ). Insecticide volumes were recorded for comparison among treatments and expressed as $\mathrm{kg}$ active ingredient.

Mean yield measurements $(\mathrm{kg})$ by plot were derived from sampling the middle four rows $\left(55.7 \mathrm{~m}^{2}\right)$ of plots bordered by trap crops and conventionally managed plots, as well as the trap crops $\left(55.7 \mathrm{~m}^{2}\right)$. Plots were harvested on 9 September 2002 using a two row digger, after which tubers were collected by hand. Despite the fact that tuber sets tended to be numerous, individual tubers were commonly undersized for all treatments and grading for percent U.S. no. 1 was inappropriate.

Total mean insect density by life stage data in conventional and plots bordered by trap crops were analysed using SAS PROC GLM repeated measures analysis of variance (RMANOVA), with sampling days as the repeated measure and plot type (conventional, bordered by attractant-treated trap crop, or bordered by untreated trap crop) as the treatment factor. One-way ANOVA was used to analyse LAI, insecticide volume and yield. SAS PROC TTEST (paired $t$-test) (SAS Institute, Inc.) was used to analyse total mean insect density by life stage in attractant-treated and untreated trap crops. Square root data transformation $\left(x=y^{1 / 2}\right)$ was conducted to meet conditions of normality. Mean comparisons were conducted using Tukey's $W$ Procedure (SAS Institute, Inc.).

\section{Results}

\section{Pitfall trap study}

Under laboratory conditions, cigarette filters released a total of $77.64 \mu \mathrm{g}$ of the three-component kairomone for each 6-h collection period. Release rates for individual kairomone components over 6-h collections were: $(Z)-3$-hexenyl acetate, $25.18 \pm 2.66 \mu \mathrm{g}$; (+/-)-linalool, $41.08 \pm 5.95 \mu \mathrm{g}$; and methyl salicylate, $11.38 \pm 1.52 \mu \mathrm{g}$; and hourly release rates derived from these data were: total volatiles, $12.94 \mu \mathrm{g}$, and individual components $(Z)-3$-hexenyl acetate, $4.19 \mu \mathrm{g}(+/-)$ linalool, $6.84 \mu \mathrm{g}$; and methyl salicylate, $1.89 \mu \mathrm{g}$.

Significantly more adult $L$. decemlineata were captured in baited traps than in control traps. Baited traps in the 0.30-ha field contained an average of $2.45 \pm 0.33$ beetles/day whereas control traps contained $0.32 \pm 0.75$ beetles/day $(t=6.98 ;$ d.f. $=10 ; P<0.05)$. Baited traps in the 0.10 -ha field contained an average of $2.78 \pm 0.34$ beetles/day whereas control traps contained $0.25 \pm 0.07$ beetles/day $(t=7.23$; d.f. $=9 ; P<0.05)$.

\section{Trap crop study}

Trap crop comparison. Mean densities of L. decemlineata adults, egg masses and small larvae were significantly higher in attractant-treated trap crops than in untreated trap crops, which averaged $1.63 \pm 0.08$ and $1.31 \pm 0.06$ adults $(t=-3.33 ; \quad$ d.f. $=499 ; \quad P<0.05), \quad 0.99 \pm 0.06 \quad$ and $0.79 \pm 0.05$ egg masses $(t=-2.94$; d.f. $=499 ; P<0.05)$ and $6.83 \pm 0.75$ and $3.51 \pm 0.50$ small larvae $(t=-4.15$; d.f. $=499 ; P<0.05)$, respectively. Large larvae were not included in the analysis because they did not appear before the economic threshold was reached and insecticide applications were made. Mean yield in attractant-treated $(141.2 \pm 21.4 \mathrm{~kg})$ and untreated $(141.4 \pm 21.6 \mathrm{~kg})$ trap crop plots was not significantly different $(t=0.72$; d.f. $=15$; $P>0.05)$.

Comparison of plots bordered by untreated or attractanttreated trap crops and conventionally managed plots. There was no significant effect of sampling day on insect distribution among conventional plots and plots bordered by trap crops $(\mathrm{F}=2.03$; d.f. $=17 ; \mathrm{P}>0.05)$. Insect density data collected biweekly over the course of the season were subsequently pooled for analysis and included season-wide data collected before and after insecticide application.

There were significantly more egg masses in plots bordered by untreated trap crops $(0.27 \pm 0.017)$ than in plots bordered by attractant-treated trap crops $(0.19 \pm 0.013)$ or managed conventionally $(0.17 \pm 0.013)(\mathrm{F}=18.35$; d.f. $=2$, 17; $\mathrm{P}<0.05$; Fig. $2 \mathrm{a})(n=240)$, as well as significantly more small larvae in plots bordered by untreated trap crops $(3.3 \pm 0.21)$ than in plots bordered by attractant-treated trap crops $(2.4 \pm 0.15)$ or in conventionally managed plots $(2.04 \pm 0.15) \quad(F=18.03 ;$ d.f. $=2, \quad 17 ; \quad P<0.05 ; \quad$ Fig. $2 b)$ $(n=240)$. There were significantly more large larvae in plots bordered by untreated trap crops $(1.72 \pm 0.11)$ and plots bordered by attractant-treated trap crops $(1.45 \pm 0.09)$ than in conventionally managed plots $(0.19 \pm 0.02) \quad(F=113.9 ; \quad$ d.f. $=2, \quad 17 ; \quad P<0.05 ; \quad$ Fig. $2 c)$ $(n=240)$ and significantly more adults in plots bordered by untreated trap crops $(1.37 \pm 0.052)$ and plots bordered by attractant-treated trap crops $(1.12 \pm 0.07)$ than in 
(a)

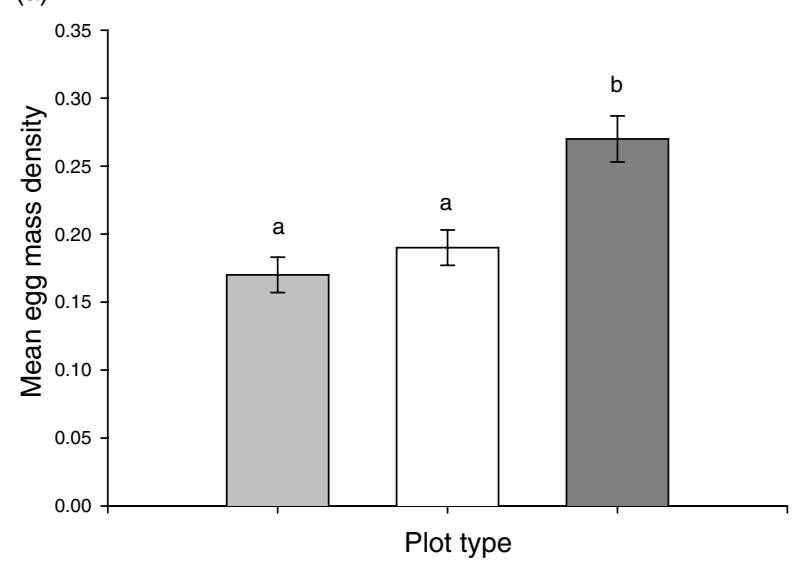

(c)

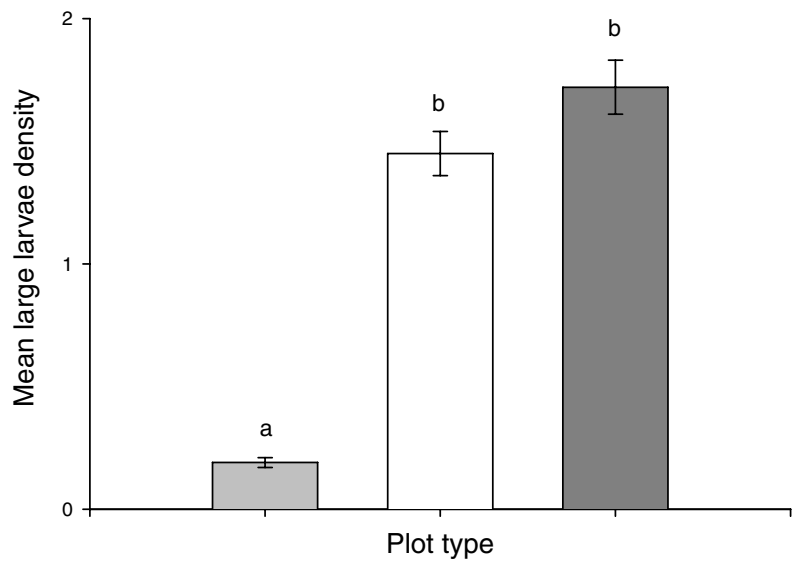

(d)

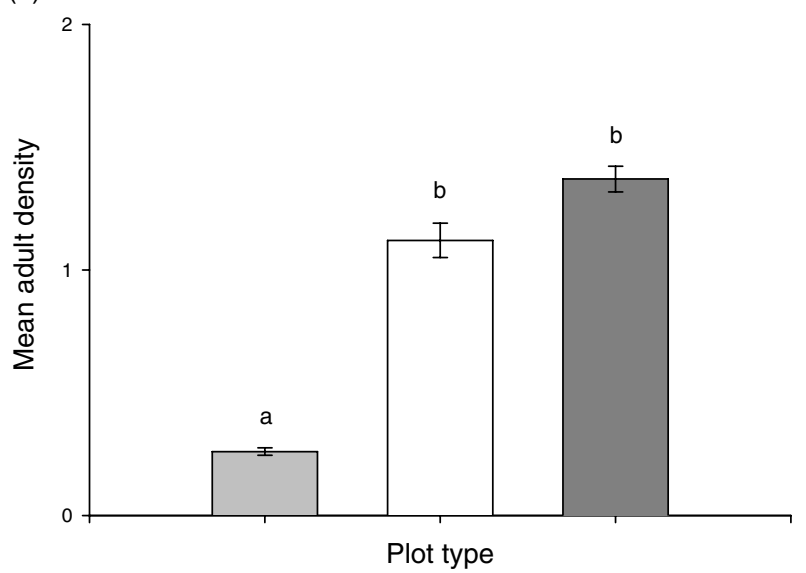

Plot type
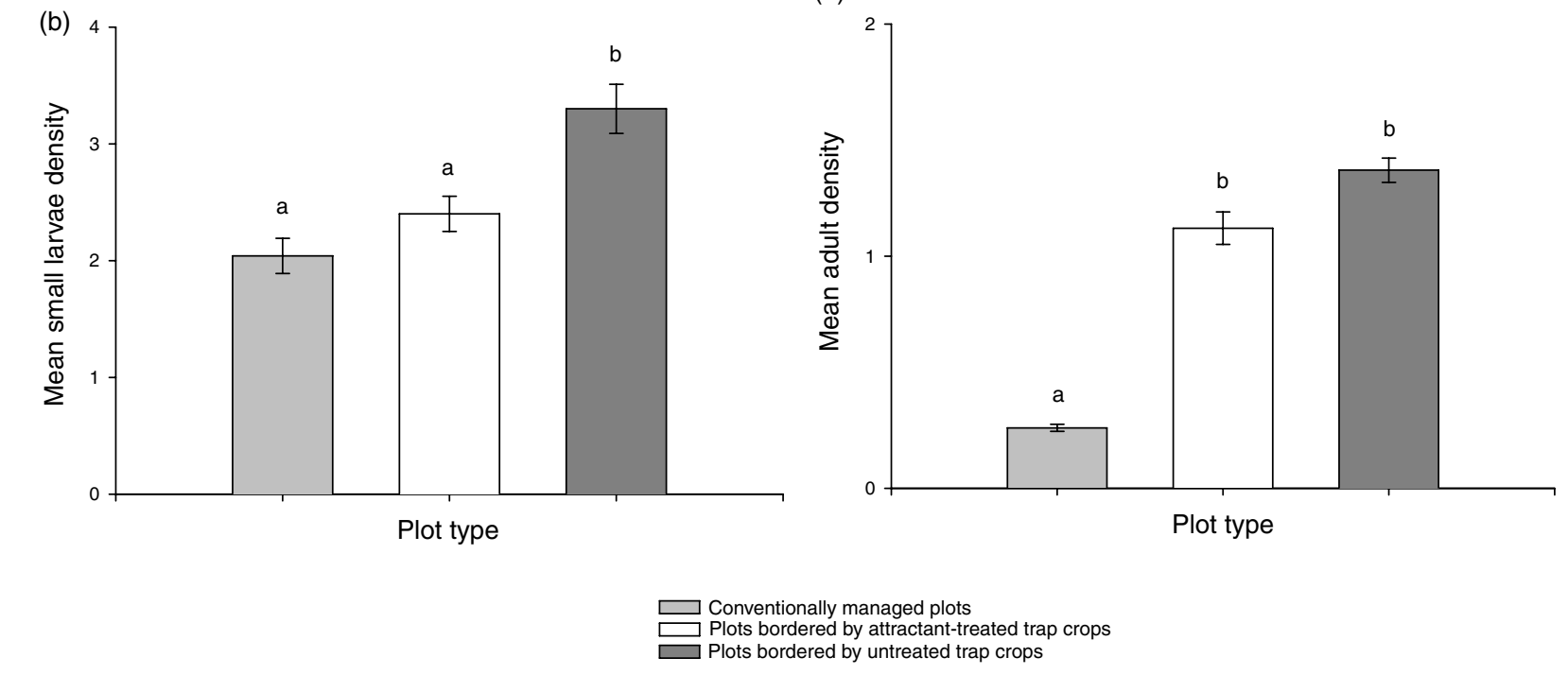

Figure 2 Mean \pm SEM density of Leptinotarsa decemlineata in conventionally managed plots, main plots bordered by attractant-treated trap crops, and main plots bordered by untreated trap crops. (a) Egg masses. (b) Small larvae. (c) Large larvae. (d) Adults.

conventionally managed plots $(0.26 \pm 0.015)(F=206.31$ d.f. $=2,17 ; P<0.05$; Fig. 2 d) $(n=240)$.

Mean densities of all four $L$. decemlineata life stages in the untreated reference control plot (10-30 May 2002) were greater than in both conventionally managed plots and plots bordered by trap crops (Table 1). The general mean density ranking for all life stages in these plots was conventionally managed plots $<$ plots bordered by attractanttreated trap crops $<$ plots bordered by untreated trap crop $<$ reference control plot.

Insecticide volume. Insect densities meant that all trap crop plots and the plots they bordered needed to be sprayed once whereas conventionally managed plots required two applications. Total insecticide input for plots and associated trap crop was $0.0027 \mathrm{~kg}$ active ingredient whereas the total input in conventionally managed plots was $0.0047 \mathrm{~kg}$ active ingredient. Consequently, significantly less insecticide was applied to plots bounded by attractant-treated and untreated trap crops than conventionally managed plots $(F=54000.5 ;$ d.f. $=3 ; P<0.05)(n=16)$ whereas insecticide levels in the plots bordered by either type of trap crop were not significantly different.

Leaf area index measurement. Leaf area index of conventionally managed plots $(4.35 \pm 0.11)$, plots bordered by attractant-treated trap crops $(3.62 \pm 0.17)$ and plots bordered by untreated trap crops $(1.31 \pm 0.08)$ were all statistically different from one another $(F=154.05$; d.f. $=2,21$; $P<0.05)$ (Fig. 3) $(n=96)$. The general mean canopy area ranking by plots was conventionally managed plots $>$ plots bordered by attractant-treated trap crops $>$ plots bordered by untreated trap crops.

Yield. Mean yield $(\mathrm{kg})$ in attractant-treated and untreated trap crops was $141.2 \pm 8.3$ and $138.3 \pm 10.3$, respectively. Mean yield $(\mathrm{kg})$ in the sample areas of plots bordered by untreated trap crops $(77.8 \pm 12.6)$ was significantly lower 
Table 1 Mean \pm SEM insect density per plant by treatment and life stage for treatment plots and untreated reference control plot

\begin{tabular}{|c|c|c|c|}
\hline Life stage & Treatment & Density \pm SEM & Reference control density $\pm \mathrm{SEM}^{*}$ \\
\hline Egg mass & $\begin{array}{l}\text { Conventionally managed } \\
\text { Bordered by attractant-treated trap crops } \\
\text { Bordered by untreated trap crops }\end{array}$ & $\begin{array}{l}0.17 \pm 0.013^{a} \\
0.19 \pm 0.013^{a} \\
0.27 \pm 0.017^{b}\end{array}$ & $0.46 \pm 0.05$ \\
\hline Small larva & $\begin{array}{l}\text { Conventionally managed } \\
\text { Bordered by attractant-treated trap crops } \\
\text { Bordered by untreated trap crops }\end{array}$ & $\begin{array}{r}2.04 \pm 0.15^{\mathrm{a}} \\
2.4 \pm 0.15^{\mathrm{a}} \\
3.3 \pm 0.21^{\mathrm{b}}\end{array}$ & $7.23 \pm 0.5$ \\
\hline Large larva & $\begin{array}{l}\text { Conventionally managed } \\
\text { Bordered by attractant-treated trap crops } \\
\text { Bordered by untreated trap crops }\end{array}$ & $\begin{array}{l}0.19 \pm 0.02^{\mathrm{a}} \\
1.45 \pm 0.09^{\mathrm{b}} \\
1.72 \pm 0.11^{\mathrm{c}}\end{array}$ & $8.04 \pm 0.48$ \\
\hline Adult & $\begin{array}{l}\text { Conventionally managed } \\
\text { Bordered by attractant-treated trap crops } \\
\text { Bordered by untreated trap crops }\end{array}$ & $\begin{array}{l}0.26 \pm 0.015^{\mathrm{a}} \\
1.12 \pm 0.07^{\mathrm{b}} \\
1.37 \pm 0.052^{\mathrm{c}}\end{array}$ & $2.26 \pm 0.04$ \\
\hline
\end{tabular}

*Reference control plot terminated 1 July 2002.

Superscript letters represent mean separation results.

than in plots bordered by attractant-treated trap crops $(140.7 \pm 5.3)$ and conventionally managed plots $(156.9 \pm 9.1)$. There was no significant difference between the sample areas of plots bordered by attractant-treated trap crops and conventionally managed plots $(F=19.45$; d.f. $=2,9 ; P>0.05$; Fig. 4$)(n=12)$. Mean treatment plot yield extrapolated to a $\mathrm{kg} / \mathrm{ha}$ scale were: conventionally managed plots $(28777 \mathrm{~kg} / \mathrm{ha})$, plots bordered by attractant-treated trap crops $(25787 \mathrm{~kg} / \mathrm{ha})$ and plots bordered by untreated trap crops $(14269 \mathrm{~kg} / \mathrm{ha})$.

\section{Discussion}

The pitfall studies demonstrated clearly that the synthetic host volatile blend was attractive to postdiapause, colonizing $L$. decemlineata under field conditions. The mean number of colonizing adult $L$. decemlineata captured in attractant-baited pitfall traps was significantly greater than in control traps for both fields in 2000. Similarly,

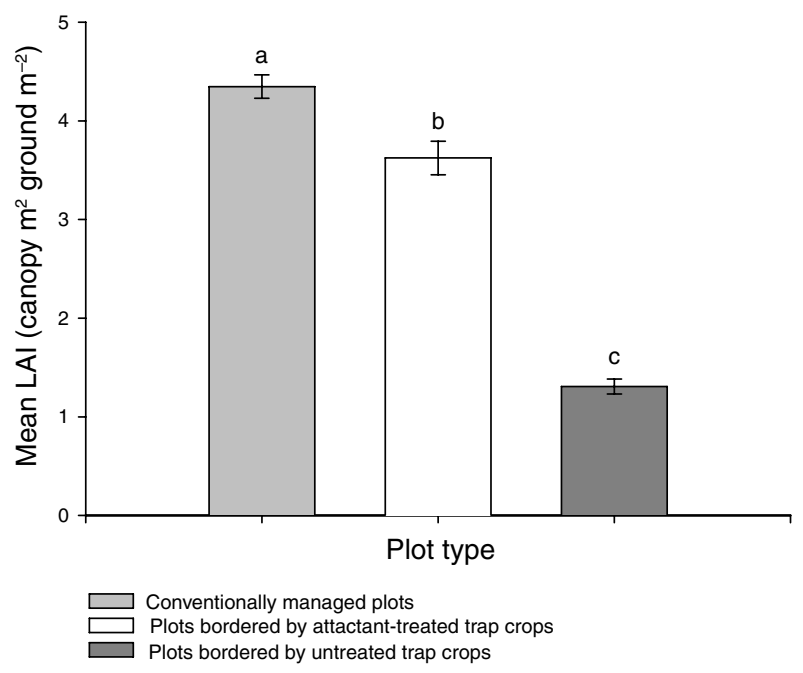

Figure 3 Mean leaf area index (canopy $\mathrm{m}^{2} /$ ground $\mathrm{m}^{2}$ ) in conventionally managed plots, main plots bordered by attractant-treated trap crops, and main plots bordered by untreated trap crops. significantly higher insect densities were observed in attractant-treated trap crops than in untreated trap crops in 2002.

The synthetic host attractant clearly increased the efficacy of otherwise untreated trap crops. Plots bordered by attractant-treated trap crops sprayed with imidacloprid when pest densities exceeded threshold had significantly fewer L. decemlineata, significantly greater plant canopy area, and significantly higher tuber yields than plots bordered by untreated trap crops, with yields that were not statistically different from conventionally managed plots.

Plots bordered by trap crops required only one insecticide application whereas conventionally managed plots required two. Total insecticide input volume for plots and associated trap crops compared with conventionally managed plots represents a $44 \%$ decrease in annual insecticide input. Consequently, by using time and space as impediments to field-wide insect colonization in combination with semiochemicals to direct pest movement, approximately half the

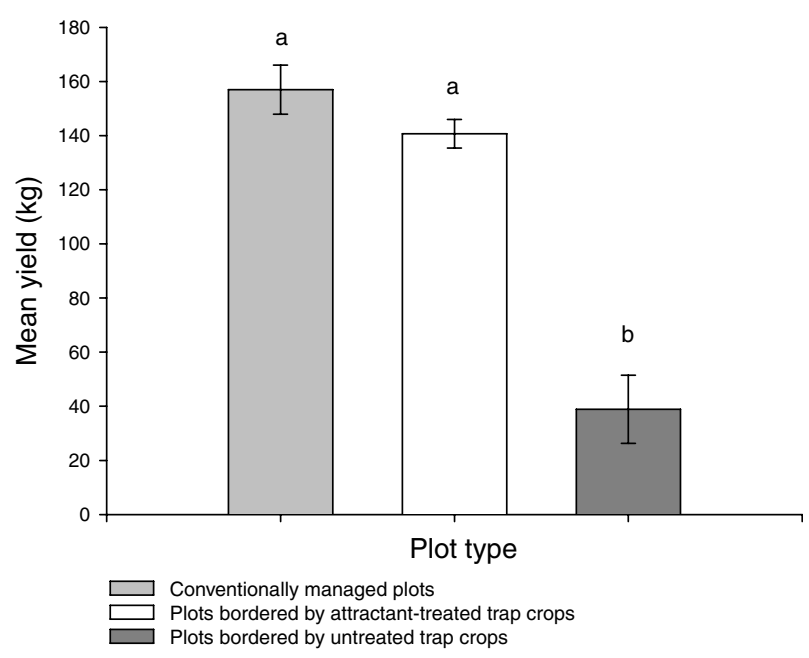

Figure 4 Mean yield ( $\mathrm{kg}$ in $55.7 \mathrm{~m}^{2}$ sample area) in conventionally managed plots, main plots bordered by attractant-treated trap crops, and main plots bordered by untreated trap crops. 
amount of insecticide input was required to achieve yields that were not significantly different from those in conventionally managed plots. This determination might benefit producers by reducing management costs, resistance selection pressure and unwanted ecological impacts on the production environment.

Despite significant differences in insect density and relative canopy area between conventionally managed plots and plots bordered by attractant-treated trap crops, there were no significant differences in mean yield. Solanum tuberosum has the capacity to effectively compensate for early season foliage loss (Midmore, 1986). Dripps \& Smilowitz (1989) reported that plants damaged by $L$. decemlineata before the initiation of tubers were able to recover, but plants damaged after tuber initiation were not. It may be that early season damage sustained in plots bordered by attractant-treated trap crops compared with conventional plots was insufficient to reduce yield.

Effective pest scouting and timely management enabled us to salvage yield from the trap crop as well as treatment plot output, and these were only approximately $10 \%$ lower than in conventionally managed plots. When yield in plots bordered by attractant-treated trap crops was combined with trap crop yield, as it would be in a commercial operation, approximately $281 \mathrm{~kg}$ was produced on $585.6 \mathrm{~m}^{2}$. In comparison, approximately $157 \mathrm{~kg}$ was produced on $474.2 \mathrm{~m}^{2}$ in conventionally managed plots. Extrapolated to a scale of $585.6 \mathrm{~m}^{2}$, conventionally managed plots in this experimental system could be expected to produce only $194 \mathrm{~kg}$. This result suggests that if trap crops are managed effectively, they need not be sacrificial and can contribute considerably to overall yield.

Attractant-treated trap crops attracted significantly more colonizing adult beetles, and consequently contained significantly higher egg mass and small larvae densities, than untreated trap crops. An important implication of this is that $L$. decemlineata may have been killed in greater numbers in these areas than in untreated trap crops due to tighter aggregation facilitated by the volatile attractant application. This might account for significantly fewer L. decemlineata of all life stages in plots bordered by attractant-treated trap crops than plots bordered by untreated trap crops, suggesting that semiochemicals can direct pest colonization, facilitate aggregation and increase the efficacy of other management components.

One potential means of deploying this alternative strategy more effectively on a commercial scale would be to make in-furrow systemic insecticide application during early trap crop planting instead of using a foliar insecticide. The use of systemic insecticides may better protect primary L. decemlineata feeding areas that are difficult to cover with a foliar-sprayed insecticide (Riedel \& Welty, 2002). Foliar application of a synthetic host attractantinsecticide combination product (attracticide) is an additional alternative.

In conclusion, the addition of the synthetic host attractant clearly augmented the efficacy of otherwise untreated trap crops, with specific regard to L. decemlineata management and potato production. Although insect density reduction in plots bordered by attractant-treated trap crops was not as effective and plant canopy measurements were not quite as high compared with those in conventionally managed plots, yields were not significantly reduced. By contrast, plots bordered by untreated trap crops produced significantly lower yield. Our results demonstrate the potential effectiveness of a synthetic host plant attractant for $L$. decemlineata management and provide a tool for reduced-input pest management.

\section{Acknowledgements}

We thank the Maine Potato Board for support and Trécé, Incorporated for supplying the synthetic host volatile attractant formulation, as well as Drs B. Hollister and J. Davis, USDA, ARS, Beltsville, Maryland, and Joseph Cannon and Steven Knapp, University of Maine, Orono, Maine, for technical assistance. J.C.D. thanks A. Mattoo for support and encouragement. Critical reviews of versions of the manuscript were gratefully provided by Professor F. E. Hanson, Department of Biological Sciences, University of Maryland, Catonsville, Maryland, Dr A. Alyokhin, University of Maine, Orono, Maine, and Dr Don Weber, USDA, ARS, Insect Biocontrol Laboratory, Beltsville, Maryland. This research was funded by the Maine Agricultural and Forest Experiment Station and USDA Cooperative Grant Agreement no. 59-1275-9-041. This is MAFES publication no. 2725.

\section{References}

Boiteau, G. (1988) Control of the Colorado potato beetle, Leptinotarsa decemlineata (Say): learning from the Soviet experience. Bulletin of the Entomological Society of Canada, 20, 9-14.

Boiteau, G. (2000) Efficiency of flight interception traps for adult Colorado potato beetles (Coleoptera: Chrysomelidae). Journal of Economic Entomology, 93, 630-635.

Bolter, C.J., Dicke, M., Van Loon, J.J.A., Visser, J.H. \& Posthumus, M.A. (1997) Attraction of Colorado potato beetle to herbivore-damaged plants during herbivory and after its termination. Journal of Chemical Ecology, 23, 1003-1023.

Bozhkov, D.K. (1985) Use of some aspects of the biology of the Colorado potato beetle ( $L$. decemlineata) for its control. Ekologia Bulgaria, 16, 75-77.

Casagrande, R.A. (1987) The Colorado potato beetle: 125 years of mismanagement. Bulletin of the Entomological Society of America, 33, 142-150.

Chausov, E.G. (1976) The trustworthiness of forecasts. Zashchita Rastenii, 12, 42-43.

DeWilde, J. (1976) The olfactory component in host plant selection in the adult Colorado potato beetle (Leptinotarsa decemlineata Say). Symposium Biologica Hungarica, 16, 291-300.

Dickens, J.C. (1989) Green leaf volatiles enhance aggregation pheromone of boll weevil, Anthonomus grandis. Entomologia Experimentalis et Applicata, 52, 191-203.

Dickens, J.C. (1999) Predator-prey interactions: olfactory adaptations of generalist and specialist predators. Agricultural and Forest Entomology, 1, 47-54. 
Dickens, J.C. (2000) Orientation of Colorado potato beetle to natural and synthetic blends of volatiles emitted by potato plants. Agricultural and Forest Entomology, 2, 167-172.

Dickens, J.C. (2002) Behavioural responses of larvae of the Colorado potato beetle, Leptinotarsa decemlineata (Coleoptera: Chrysomelidae), to host plant volatile blends attractive to adults. Agricultural and Forest Entomology, 4, 309-314.

Dorozhkin, N.A., S.I.Bel'skaya \& A.A. Meleshkevich. (1975) Combined protection of potatoes. Zashchita Rastenii, 7, 6-8.

Dripps, J.E. \& Smilowitz, Z. (1989) Growth analysis of potato plants damaged by Colorado potato beetle (Coleoptera: Chrysomelidae) at different plant growth stages. Environmental Entomology, 18, 854-867.

Forgash, A.G. (1985) Insecticide resistance in the Colorado potato beetle. Proceedings of the Symposium on the Colorado Potato Beetle, XVII International Congress of Entomology (ed. by D. N. Ferro and R. H. Voss), pp. 33-52. Massachusetts Experiment Station, Amherst, Massachusetts.

French, N.M.I.I., Heim, D.C. \& Kennedy, G.G. (1992) Insecticide resistance patterns among Colorado potato beetle, Leptinotarsa decemlineata (Say) (Coleoptera: Chryso-melidae), populations in North Carolina. Pesticide Science, 36, 95-100.

Hardee, D.D. (1982) Mass trapping and trap cropping of the boll weevil Anthonomus grandis Bohrman. Insect Suppression with Controlled Release Pheromone Systems, Vol. 2 (ed. by A. F. Kydonieus and M. Beroza), pp. 65-71. CRC Press, Boca Raton, Florida.

Hare, J.D. (1990) Ecology and management of the Colorado potato beetle. Annual Review of Entomology, 35, 81-100.

Heath, R.R. \& Manukian, A. (1994) An automated system for use in collecting volatile chemicals released from plants. Journal of Chemical Ecology, 20, 593-608.

Hokkanen, H.M.T. (1991) Trap cropping in pest management. Annual Review of Entomology, 36, 119-138.

Ioannidis, P.M., Grafius, E. \& Whalon, M.E. (1991) Patterns of insecticide resistance to azinphosmethyl, carbofuran, and permethrin in the Colorado potato beetle (Coleoptera: Chrysomelidae). Journal of Economic Entomology, 84, 1417-1423.

Ioriatti, C. \& Bouvier, J.C. (2000) La resitenza agli insectticidi; il caso della carpocapsa (Cydia pomonella L.). Informatore Fitopatologico, 9, 5-10.

Jones, R.I. \& Marquardt, T.E. (1987) Monitoring of aldicarb residues in Long Island, New York potable wells. Archives of Environmental Contamination and Toxicology, 16, 643-647.

Kennedy, G.G. \& French, N.M.I.I. (1994) Monitoring resistance in Colorado potato beetle populations. Advances in Potato Pest Biology and Management (ed. by G. W. Zehnder, M. L. Powelson, R. K. Jansson and K. V. Raman), pp. 278-293. APS Press, St Paul, Minnesota.

Landolt, P.J., Tumlinson, J.H. \& Alborn, D.H. (1999) Attraction of Colorado potato beetle (Coleoptera: Chrysomelidae) to damaged and chemically induced potato plants. Environmental Entomology, 28, 973-978.

Martel, J.W., Alford, A.R. \& Dickens, J.C. (2004) Laboratory and greenhouse evaluation of a synthetic host volatile attractant for Colorado potato beetle, Leptinotarsa decemlineata (Say). Agricultural and Forest Entomology, 7, 71-78.

McIndoo, N.E. (1926) An insect olfactometer. Journal of Economic Entomology, 19, 545-571.
Metcalf, R.L. (1985) Plant kairimones and insect pest control. Illinois Natural History Survey Bulletin, 33, 175-198.

Midmore, D.J. (1986) Repuesta de la planta de papa (Solanum spp.) al daño de insectos: algunos efectos de compensación. Memorias del Curso Sobre 'Control Integrado de la Papa'. International Potato Cent (CIP) (ed. by L. Valencia), pp. 176-200. Institute Colombiano Agropecuario (ICA), Colombia.

Olkowski, W., Saiki, N. \& Daar, S. (1992) IPM options for Colorado potato beetle. IPM Practitioner, 14, 1-22.

Olson, E.R., Dively, G.P. \& Nelson, J.O. (2000) Baseline susceptibility to imidacloprid and cross resistance patterns in Colorado potato beetle (Coleoptera: Chrysomelidae) populations. Journal of Economic Entomology, 93, 447-458.

Rahardja, U. \& Whalon, M.E. (1995) Inheritance of resistance to Bacillus thuringiensis subsp. tenebrionis CryIIIA delta-endotoxin in Colorado potato beetle (Coleoptera: Chrysomelidae). Journal of Economic Entomology, 88, 21-26.

Riedel, M. \& Welty, C. (2002) Ohio Vegetable and Potato. Growers Association, Vegetable Q5. March 2002. http://www.ohiovegetables.org/ovpga/ovpgawebengine.nsf/\$LookupPageID/JHUD58EM3X/?OpenDocument.

Schanz, M. (1953) Der Geruchssinn des Kartoffelkäfers (Leptinotarsa decemlineata Say). Zeitschrift fuer Vergleichende Physiologie, 35, 353-379.

Shani, A. (1991) Role of pheromones in integrated pest management (survey conducted in July - November, 1990). USA/Israel BARD Workshop, New Targets for Insect Management in Crop Protection, Jerusealem. Phytoparasitica, 19, 337-338.

Smart, L.E., Blight, M.M., Pickett, J.A. \& Pye, B. (1994) Development of field strategies incorporating semiochemicals for the control of the pea and bean weevil, Sitona lineatus L. Crop Protection, 13, 127-135.

Stewart, J.G., Kennedy, G.G. \& Sturz, A.V. (1997) Incidence of insecticide resistance in populations of Colorado potato beetle, Leptinotarsa decemlineata (Say) (Coleoptera: Chrysomelidae) on Prince Edward Island. Canadian Entomologist, 129, 21-26.

Van der Ent, L.J. \& Visser, J.H. (1991) The visual world of the Colorado potato beetle. Experimental and Applied Entomology: Proceedings of the Netherlands Entomological Society (NEV), 2 , $80-85$.

Visser, J.H. \& Avé, D.A. (1978) General green leaf volatiles in the olfactory orientation of Colorado beetle, Leptinotarsa decemlineata. Entomologia Experimentalis et Applicata, 24, 538-549.

Whalon, M.E., Miller, D.L., Hollingworth, R.M., Grafius, E.J. \& Miller, J.R. (1993) Selection of a Colorado potato beetle (Coleoptera: Chrysomelidae) strain resistant to Bacillus thuringiensis. Journal of Economic Entomology, 86, 226-233.

Wyman, J. (1995) Timing Bacillus thuringiensis var. tenebrionis Applications for Colorado Potato Beetle Control. http:// www.entomology.wisc.edu/mbcn/veg202.html.

Zehnder, G. \& Speese, J. III (1987) Assessment of color response and flight activity of Leptinotarsa decemlineata (Say) (Coleoptera: Chrysomelidae) using window flight traps. Environmental Entomology, 16, 1199-1202.

Zhao, J.-Z., Bishop, B.A. \& Grafius, E.J. (2000) Inheritance and synergism of resistance to imidacloprid in the Colorado potato beetle (Coleoptera: Chrysomelidae). Journal of Economic Entomology, 93, 1508-1514.

Accepted 30 October 2004 